Etnográfica

Revista do Centro em Rede de Investigação em

Antropologia

vol. $22(1) \mid 2018$

Vol. $22(1)$

\title{
Rugby, educación solidaria y riqueza en las elites de Buenos Aires: la construcción de una clase moral
}

Rugby, solidarity education and wealth among elites in Buenos Aires: the construction of a moral class

\section{Sebastián Gerardo Fuentes}

\section{(2) OpenEdition}

\section{Journals}

Edición electrónica

URL: https://journals.openedition.org/etnografica/5147

DOI: $10.4000 /$ etnografica. 5147

ISSN: 2182-2891

\section{Editor}

Centro em Rede de Investigação em Antropologia

\section{Edición impresa}

Fecha de publicación: 1 febrero 2018

Paginación: 53-73

ISSN: 0873-6561

\section{Referencia electrónica}

Sebastián Gerardo Fuentes, «Rugby, educación solidaria y riqueza en las elites de Buenos Aires: la construcción de una clase moral», Etnográfica [En línea], vol. 22 (1) | 2018, Publicado el 17 mayo 2018 consultado el 20 enero 2022. URL: http://journals.openedition.org/etnografica/5147 ; DOI: https:// doi.org/10.4000/etnografica.5147

\section{(c) (i) (8)}

Etnográfica is licensed under a Creative Commons Attribution-NonCommercial 4.0 International License. 


\section{Rugby, educación solidaria y riqueza en las elites de Buenos Aires: la construcción de una clase moral}

\section{Sebastián Gerardo Fuentes}

Jóvenes de sectores medios-altos y altos de Buenos Aires practican rugby y realizan prácticas educativas solidarias, en un contexto de crecimiento de las desigualdades y heterogeneización de las elites. La actual profesionalización del rugby altera el patrón del deporte amateur introduciendo el dinero en la vida deportiva de los jóvenes y exponiéndolos a sectores sociales subordinados. La extensión y resignificación de la educación solidaria católica hace legítimas antiguas prácticas de caridad, subordinando la desigualdad socioeconómica en la apelación al esfuerzo y el mérito de los pobres. Los sectores de elite construyen la clase social como clase moral, estableciendo relaciones con alteridades "de clase" que les permiten subordinar el valor del dinero/capital económico como principal desigualador social y distinguirse moralmente.

PALABRAS-CLAVE: universidad, rugby, jóvenes, moral, alteridad, amateurismo.

Rugby, solidarity education and wealth among elites in Buenos Aires: the construction of a moral class - Young people from middle-upper and upper class families take part in rugby and solidarity education in Buenos Aires, in a context of deepening inequalities and heterogeneous elites. Current rugby professionalization touches the core of this amateur sport by introducing money into young people lives and exposing them to subordinated social class. The extension and new meaning given to the solidarity Catholic education legitimize the traditional charity, subordinating the socioeconomic inequality through the discourse of effort and merit among poor people. Elites construct the social class as a moral class by setting relationships with class otherness. This allows elites to morally distinguish themselves and to subordinate the value of money/economic capital as the main factor of social inequality.

KEYWORDS: university, rugby, youth, moral, otherness, amateurism.

FUENTES, Sebastián Gerardo (sebasfuentes3@gmail.com) - Universidad de Amsterdam, Países Bajos; Conicet/Flacso, Untref, Argentina. 


\section{A MARINA, JOVEN ESTUDIANTE DE PSICOLOGÍA, LA CONOCÍ EN UNA} jornada que la universidad católica donde estudia realizaba en una villa miseria de Buenos Aires con motivo del "Día Internacional del Voluntariado", dando talleres formativos y haciendo reuniones comunitarias en una capilla católica. Si bien el marco era "católico", y quienes organizaban las actividades se reconocían como tales, las actividades no eran "religiosas", como me explicaban, sino de "promoción social", algo que la universidad viene haciendo desde hace pocos años, variando así su tradición "misionera” explícitamente evangelizadora. ${ }^{1}$ En el reparto de tareas y actividades, a Marina le tocó dar una charla a los jóvenes pobres del barrio sobre "técnicas de estudio". Al terminar, un abogado egresado de la universidad, recién nombrado juez, que participaba del taller, les explicaba a los jóvenes que cualquiera de ellos podía llegar a ser juez como él, "si estudia, trabaja y se esfuerza".

Marina se encontraba junto a otros predicando sobre los valores del esfuerzo y el estudio, construyendo una relación de jerarquía moral entre ella, educada formalmente, hija y nieta de profesionales con un buen pasar económico, y los jóvenes pobres de la villa, que aún luchaban por finalizar su escuela secundaria en instituciones públicas. Su práctica resignificaba lo que sus padres y/o abuelos habían hecho, filantropía o caridad católica en la ayuda material a los sectores postergados, solo que en ella la dimensión religiosa aparecía subordinada y reemplazada por un discurso moral y educativo. En esas instancias e interacciones entre jóvenes con recursos económicos y jóvenes pobres, la desigualdad parecía sostenerse en una relación moral donde quien "ayuda" se ubica como modelo de logro meritocrático e individual. Este nuevo rostro con el que los sectores católicos de elites enfrentaban una sociedad desigual requería un análisis más profundo que ser categorizado como mera filantropía, donde la educación en "valores" aparecía como una distinción social de quienes participaban de esas instancias.

La formación de valores organiza otra práctica extendida entre los jóvenes de elite en Buenos Aires: el rugby masculino. En los clubes tradicionales donde se practica, los sectores medios-altos y altos de Buenos Aires invierten y ponen en circulación capitales, desarrollando estrategias de reproducción social, como condicionar los matrimonios de la generación subsiguiente, o establecer una red social horizontal, los “amigos de toda la vida”. Pedro, jugador de rugby - o "rugbier", como comúnmente se llaman -, tiene 23 años y está a punto de terminar su carrera universitaria de contador; cuenta con una serie de contactos en empresas nacionales y multinacionales para insertarse laboralmente. Esos contactos combinan parentesco y amistades: el amigo de un primo, el padre de un amigo, etc., todos pertenecientes al "mundo del rugby". La producción de profundos lazos de amistad y la formación en valores como la lealtad y 
el compañerismo son distintivos de este deporte amateur, cuyos actores aún intentan defenderlo frente a la profesionalización que se inició hacia 2010 en la Argentina.

Pedro pertenece a una de las instituciones con mayor antigüedad en la práctica de este deporte amateur, y que ha hecho del mismo una insignia del valor social y moral de sus miembros, el Club Universitario de Buenos Aires (CUBA):

"Hoy, nuestra institución puede estar orgullosa, más que de los logros en lo material y lo edilicio, de la libertad, la camaradería y la preservación de nuestra concepción del deporte amateur que rechaza todo tipo de retribución por los logros deportivos". ${ }^{2}$

CUBA ha sido uno de los clubes que con mayor ahínco ha defendido el amateurismo deportivo del rugby en Buenos Aires. La clave de su defensa se halla en el rechazo de la "retribución", es decir, el pago de un salario y la intermediación del capital económico, el deporte hecho mercado entre jugadores que no necesitarían de ese recurso, puesto que deberían profesionalizarse vía los estudios universitarios. Se defiende un deporte moral en el sentido civilizador y, sobre todo, la distinción social de quienes lo practican.

El propósito de este artículo es comprender cómo el rugby masculino y las prácticas educativas solidarias contribuyen a la construcción del valor y la formación de las alteridades de clase en clave moral. La importancia de ambas prácticas radica en que en ellas se juega la presentación del grupo y su valor frente a otros sectores sociales (Peristiany 1968). La construcción de una posición social considerada de privilegio requiere el esfuerzo y trabajo de quienes aspiran a producirla o mantenerla. En sociedades desiguales como la Argentina, donde el cuestionamiento de las jerarquías sociales se ha condensado en un sentimiento de nación percibida como "igualitaria", las posiciones de privilegio requieren un particular trabajo de legitimación. Los "valores" que se invocan para sostener la desigualdad, desde el punto de vista de quienes ocupan las posiciones de arriba (Nader 1969), se anclan en prácticas que no solo intervienen a nivel del grupo que las realiza, sino también en contacto con actores/grupos sociales considerados "otros".

Las prácticas abiertamente elitistas son cuestionadas y cuestionables en la Argentina, a partir de procesos históricos del siglo XX asociados a la movilidad social, el acceso irrestricto a la educación, la movilización política, etc. Desde la última dictadura militar (1976-1983), se dio un proceso que implicó, por un lado, el crecimiento de las desigualdades sociales - medida en términos

2 Website del club, en < http://www.cuba.org.ar/institucional/crear-un-segundo-hogar-para-los-universitarios > (última consulta en febrero 2018). 
de ingresos económicos y de su distribución -, el incremento de la pobreza y el desempleo, la caída de los sectores medios y la emergencia de un reducido grupo de sectores medios en ascenso, simbolizada en la figura y categoría del "nuevo rico", todo ello acrecentado durante la década del 90, y que eclosiona en una crisis social y política en 2001 . Si bien ya entrados los 2000 se inicia un ciclo político y social donde se desarrollan políticas que permiten la atenuación de algunas desigualdades (Kessler 2014), como el acceso a servicios públicos, mejora en el nivel de ingresos y baja en el desempleo, las consecuencias que esta breve historia de las desigualdades produjo en cómo las elites perciben y sobre todo construyen su lugar en la sociedad aún resta por conocerse.

Las investigaciones que han abordado al estudio de los sectores privilegiados, dominantes, las elites, la clase alta, etc., han discutido y avanzado en el análisis de las redes sociales, el estudio del parentesco, y la relevancia de su posicionamiento en la nación, así como en la importancia de la educación y formación de las nuevas generaciones (Lima 2000; Marcus 2000; Piscitelli 2006; Badaró 2009; Tiramonti y Ziegler 2008; Perosa 2009; Khan 2011 ; Méndez 2013; entre otros). A partir de investigaciones recientes para el caso argentino (Heredia 2005; Gessaghi 2016; Fuentes 2015a), podemos indicar una marcada heterogeneización de las elites, no solo en el campo de poder que ocupan o aspiran a ocupar - económico, cultural, político, etc. -, sino también en la construcción de identidades y pertenencias, circuitos sociales y educativos e imaginarios en los que se referencian. Sus espacios de pertenencias, aunque parezcan homogéneos desde fuera, cuando son reconstruidos desde dentro asoman diferencias y heterogeneidades que nos permiten afirmar, siguiendo a Lamont (1992), que las fronteras sociales y morales parecen más porosas (Chaves, Fuentes y Vecino 2016).

Las desigualdades sociales y jerarquías culturales se producen en las interacciones y en los sistemas sociales donde está en juego el valor de los grupos y los individuos. Mi interés es analizar una relación poco explorada en la investigación etnográfica: el aporte de las prácticas deportivas y las formativas a la construcción de relaciones jerárquicas entre sectores de clase, particularmente al carácter moral de esas diferencias hechas desigualdades. ${ }^{3}$ La potencialidad del rugby masculino y de la educación solidaria para comprender la construcción de alteridades sociales se revela en el proceso en el que están implicadas y en la relación que ambas visibilizan con uno de los grandes diacríticos que organizan la desigualdad: el capital económico o, como lo denominan los actores, el dinero.

3 Como el trabajo de Archetti (2003), que estudió en profundidad las prácticas deportivas y su historia. De todos modos, nos distanciamos del énfasis que Archetti dio en su trabajo a la relación entre deportes y construcción de la nación, enfatizando aquí su dimensión de clase (Bourdieu 1988; Besnier 2012). 
El rugby amateur es uno de los deportes emblemáticos de elite en Buenos Aires, espacio para la producción de masculinidad con una serie de "valores" - como el esfuerzo, el compañerismo, etc. - que son atribuidos a una moral de clase (alta o distinguida), en oposición al popular y masivo fútbol (Alabarces 2013; Fuentes 2015b). La distinción social del rugby se encuentra cuestionada por la profesionalización mediante dos vías. Primero, por la trayectoria deportiva de los rugbiers que realizan una carrera profesional en clubes del exterior (Fuentes y Guinness 2018). A nivel global el rugby inició su profesionalización en 1995, por decisión de las uniones de rugby de las principales naciones que practican este deporte, mientras en Argentina los clubes se mantuvieron amateur. Los clubes europeos empezaron a contratar a jugadores argentinos, produciéndose una migración de los mejores hacia el exterior. Segundo, por el flujo de recursos económicos de la industria televisiva y las uniones regionales y global (World Rugby) que empujan la actual profesionalización local, y que fomentan la dedicación exclusiva de los jugadores al deporte, en detrimento de su trayectoria como estudiantes universitarios. Este movimiento amplía el público del rugby y lo acerca a nuevos sectores sociales, en la vidriera de la retórica nacionalista que muestran las publicidades (Alabarces 2013). El rugby, emblema del valor de la elite empieza a horadarse, al perfilarse como opción "laboral" para jóvenes de este u otro sector social, explicitando el rol del dinero como organizador de la práctica.

Las prácticas formativas "solidarias" como aquella en la que participó Marina, se extienden progresivamente en las instituciones educativas, son realizadas por jóvenes varones y mujeres, en este caso de sectores medios-altos y altos, hacia niños/as y jóvenes de sectores más pobres. Están organizadas de modos cada vez más profesionales, con personal destinado específicamente a la organización de actividades, y en el caso de las universidades con producciones como sistematizaciones de experiencias, jornadas, etc. (Fuentes 2016). Desde la década del 90, se formalizan como actividades curriculares en escuelas secundarias de sectores medios-altos y altos (Tiramonti y Ziegler 2008) y como voluntariados, misiones o actividades "solidarias" en universidades públicas y privadas que resignificaron la tradicional "caridad” y filantropía de elite. Su extensión y profesionalización permite construir una juventud "solidaria", tanto frente a quienes otorga su ayuda como frente a la sociedad, presentándose como una elite comprometida y "fuera de la burbuja" de su riqueza - como relataba una profesora involucrada en estas prácticas - o del capital económico al que intentan dar un sentido y un "valor" cuando su posesión es cuestionada.

Las jerarquías y los sentidos otorgados a la riqueza cambian de acuerdo a la estructura de clases y las relaciones entre las mismas (Pitt-Rivers 1968; Lomnitz 1982). Frente a nociones corrientes que ubican a las elites por fuera de presiones sociales, retomo desarrollos previos (Marcus 2000; Nader 1969; 
Gessaghi 2016) que indican que las transformaciones sociales y culturales también las afectan. Asimismo, cuestiono ideas sobre el aislamiento social de las elites, sobre todo algunos aportes realizados por Svampa (2004) que reifican la relación entre elites y sectores empobrecidos por medio de la metáfora del muro del barrio cerrado. Desde una perspectiva relacional, el crecimiento de las desigualdades no se explica por el aislamiento entre ricos y pobres, propiciado por las ventajas que acumularon los primeros.

En el caso argentino, la politización y movilización política de los distintos sectores de clase subordinados hacen que las elites no puedan construir una posición de exterioridad en relación a ellos. La distinción social de los sectores altos fue históricamente construida en función de diferencias hechas desigualdades por medio de posiciones y discursos morales: las elites ilustradas de fines del siglo XIX y principios del XX, por ejemplo, construían su legitimidad en su educación formal y en el discurso moral de la civilización y la modernidad (Losada 2009) que simbolizaban frente a un pueblo al que entendían como desorganizado. Las clasificaciones morales sostienen y legitiman las desigualdades socioeconómicas, y las experiencias educativas se hacían condición necesaria pero no suficiente para la construcción de la jerarquía social. Las trayectorias de los grupos privilegiados muestran que, aunque las credenciales educativas formales contribuyen a la construcción o reproducción del prestigio, en sociedades desiguales como las latinoamericanas, y específicamente la argentina (Ziegler y Gessaghi 2012), las mismas no se traducen automáticamente en vías de consagración social o legitimación de la posición de privilegio por parte de otros actores.

Por ello la decisión de combinar el estudio de las prácticas educativas ${ }^{4}$ con las deportivas, que constituyen un espacio privilegiado para el análisis de las clases sociales (Bourdieu 1988) que los deportes tienen a reforzar, aunque nunca de modos determinantes, puesto que la asociación entre clase social y práctica deportiva es inestable (Besnier y Brownell 2012). ${ }^{5}$ Desde un trabajo etnográfico abierto al análisis de las clasificaciones nativas (elites, clase alta, grupo dominante, clase privilegiada, etc.), no considero a la clase como punto de partida o presupuesto, sino como una construcción pasible de ser analizada en sus tensiones, siguiendo el planteo de Besnier (2012) sobre las tensiones

4 La etnografía educativa indica la pertinencia de considerar lo formativo desde una perspectiva amplia que incluye pero no permanece sólo en la escolarización y/o la educación formal (Neufeld 2000; Rockwell 2009; Gusmão 2009).

5 Para Bourdieu (2013) el rugby en Francia estaba asociado a un habitus propio de los sectores trabajadores, aunque no consideró la historia particular: al ser llevado por Pierre de Coubertin desde Inglaterra a fines del siglo XIX, fue un instrumento para promover el orgullo de la burguesía francesa. Solo luego se expandió hacia el sur y quedó asociado al sector de clase de origen del mismo Bourdieu, quien lo practicó (Besnier 2012). Actualmente es una práctica de sectores medios burgueses que, como en Argentina, se diferencia del masivo fútbol. 
de clase entres los jugadores de rugby tonganos en Japón. A partir de los aportes de Lomnitz (1982) y Fonseca (2005), me interesa recuperar el sentido y la experiencia de los sujetos en relación a la misma, su modo de significarla, para sostener un acercamiento etnográfico y no determinista desde el punto de vista económico, que revele los actuales procesos de configuración de las relaciones de clase.

La investigación etnográfica que realizo desde 2008 entre jóvenes y familias de sectores medios-altos y altos de Buenos Aires me llevó a acceder diversos espacios que me permitían prestar atención a la reproducción social (Rockwell 2009), observando y acompañando a los actores en las prácticas deportivas, entrenamientos, partidos, eventos institucionales, experiencias de "salida" de la universidad y el colegio y otras iniciativas "solidarias" hacia barrios/territorios pobres, etc. Como parte del trabajo de campo recopilé y analicé material documental de instituciones educativas y clubes, y mantuve conversaciones y entrevistas abiertas con innumerables actores que me permitieron reconstruir trayectorias y experiencias. ${ }^{6}$

\section{EDUCACIÓN, CATOLICISMO Y RUGBY \\ EN LOS SECTORES MEDIOS-ALTOS Y ALTOS}

Los jóvenes entre los cuales realicé la etnografía se reconocen como parte del "mundo del rugby". Residen en los barrios residenciales y/o cerrados de/en los distritos con mayor riqueza de Buenos Aires, donde viven los sectores sociales profesionales, empresarios y familias reconocidas, además de lo que los establecidos consideran como "nuevos ricos" (Svampa 2001) - familias que se enriquecieron y ascendieron "recientemente" y que no pueden invocar la antigüedad de sus pares. Sus hogares poseen lo que demográficamente se denomina clima educativo alto, con padres y madres con estudios universitarios que se desempeñan en empresas familiares, en estudios de abogados reconocidos, en el Estado (en el poder judicial, en muchos casos), o en la dirección de empresas nacionales o internacionales. Son familias cuyos varones se educan en la universidad desde principios del siglo XX.

Estos jóvenes desarrollan su escolaridad en instituciones de gestión privada, muchas de ellas católicas. El hecho de que este tipo de escolarización implique el pago de cuotas mensuales, en algunos casos muy costosas, no hace que el capital económico de las familias sea el único factor de diferenciación. Algunas de estas escuelas son valoradas en función de su tradición, es decir, tienen un prestigio que asocia positivamente la antigüedad con la calidad y confiabilidad de lo que allí sucede y se enseña. Esas escuelas y universidades católicas, junto a otras no católicas, conforman un circuito educativo donde los estudiantes y 
sus familias forman redes de conocimiento mutuo, espacios donde se recrea el mismo prestigio que las familias otorgan a las instituciones que las nuclean.

La pertenencia al catolicismo no es una propiedad excluyente del circuito del rugby, pero es común que las familias se reconozcan católicas más allá de sus prácticas religiosas, lo cual nos permite plantear al catolicismo como un espacio de pertenencia y prestigio social. La familia de Gustavo, por ejemplo, es una reconocida familia católica de CUBA: su esposa, sus hijos y él mismo asistieron a distintas escuelas católicas con "tradición". Son reconocidos, además, porque integran un movimiento eclesial que se caracteriza por la renovación de y en la fe católica, y en ese mismo movimiento y en las escuelas a donde asisten sus hijos realizan acciones solidarias, a menudo aprovechando la red de instituciones católicas ubicadas en los barrios pobres (parroquias, capillas, etc.). Los miembros varones de esa familia son reconocidos como del "rugby", llegando incluso a integrar la selección nacional. En una conversación, Gustavo aclaraba su pertenencia católica: "y es raro que encuentres a un judío acá". Su pertenencia se nutre de un reconocimiento del catolicismo como religión de pertenencia mayoritaria y dominante en Argentina (Mallimaci 2015) que nuclea a todos los sectores de clase bajo la asociación entre identidad católica e identidad nacional. En ese espacio de pertenencia, ser católico conlleva la responsabilidad social de ayudar al "pobre".

Me interesa remarcar la alteridad de clase en su discurso - y en el de otros entrevistados - donde la referencia al judío como "otro" combina relaciones entre clase social, religión y la relación con el dinero. Construye una alteridad "religiosa", la judía, cuyos capitales (económicos, escolares, profesionales, etc.) los habilitaría a poseer una casa en un barrio cerrado o pertenecer a un club selecto. En Buenos Aires, las familias judías son identificadas como clases medias y clases altas, y lo que tienen en común los católicos de elite con ellas es el desarrollo/acumulación de capital cultural escolar además del capital económico, que puede variar en su volumen. La mención a pertenencias evangélicas o pentecostales solo las escuché cuando se referían a la alteridad religiosa de los sectores populares, es decir, a aquellos que son "otros" (de clases subordinadas) y compiten con el catolicismo en las villas y asentamientos pobres. Estas alterizaciones justifican nuestra intención de considerar la pertenencia religiosa como pertenencia de clase, y señalan que el dinero/capital económico es un marcador de clase que se combina siempre con otros: el religioso en este caso, o como veremos, el moral. ${ }^{7}$

La relación entre familias de elite y catolicismo se construyó a partir de la emergencia de escuelas católicas a fines del siglo XIX, algunas de origen

$7 \quad$ Esto me permite enfatizar que los sectores socioeconómicos altos y medios-altos desarrollan estrategias para ubicar en sus vidas al capital económico, significarlo y darle un sentido de legitimidad social, todo lo cual es motivo constante de preocupación. 
inglés/irlandés. ${ }^{8}$ El prestigio de la educación inglesa de las escuelas se transformó en una marca de prestigio que se hacía evidente en el bilingüismo que propondrían, y en la jerarquía en la que las elites culturales y políticas de inicios del XX ubicaban a la formación y los "valores" ingleses (y franceses).

En muchas de las escuelas católicas, y desde la década del 60 en las universidades católicas recién creadas, se desarrollaron progresivamente actividades misioneras. ${ }^{9}$ Con ellas se buscaba la evangelización de los sectores populares, a la vez que se combinaban a veces con la educación popular y otros modos de promoción social en zonas empobrecidas del país. El catolicismo fue construido, desde la década de 1930, en relación a la nación (Mallimaci 2015). En ese contexto, las elites católicas se legitimaron a sí mismas al quedar asociadas, en sus prácticas de piedad y "caridad", con el amor por la patria.

La asociación entre nación, clase y compromiso con el "otro" llevó a muchos de sus jóvenes a formas de radicalización política en instancias de ayuda/promoción social, incluyendo la participación en organizaciones políticas que luego se tornan clandestinas/armadas - y que fueron perseguidas por la dictadura militar que inicia en 1976 o incluso en años previos. El contacto entre jóvenes de sectores de elite y poblaciones en situación de pobreza fue una constante en los espacios católicos que frecuentaron estas familias, y los riesgos que implicó para muchas de ellas la radicalización política (Manzano 2010) fue una marca que señaló la distinción entre el campo de la ayuda social, marcado por la iniciativa religiosa, y el campo político, considerado peligroso moral y existencialmente. A partir de los años 80 , ya en el retorno de la democracia, las iniciativas de educación solidaria y misión católica se renuevan, con el acento puesto en campañas de ayuda material y otras formas de acción que no impliquen compromiso político. ${ }^{10}$

Un proceso análogo al de la jerarquización de las escuelas católicas de origen inglés/irlandés aconteció entre las prácticas deportivas inglesas en la Buenos Aires de fines del siglo XIX, con el fútbol como modelo de la expansión imperial inglesa (Alabarces 2006). El rugby introducido por inmigrantes

8 Según Palermo (2010), migrando a la Argentina, los irlandeses transformaron la identidad negativa subordinada del contexto de Inglaterra, en una identidad positiva, dada por su inserción en la distribución de tierras en la pampa, que les facilitó ubicarse como burguesía agraria, y el peso de la educación y el hablar inglés que los ubicó en un nivel de privilegio en el campo simbólico. Esta particular inserción de los irlandeses en Argentina es distinta a lo que aconteció en otras naciones, donde ocuparon posiciones más subalternas.

9 En 1958 se aprueba la ley que permite la creación de universidades privadas en la Argentina.

10 En la década del 90, además, emerge con fuerza en el campo de la ayuda social la organización de la jerarquía católica Caritas Argentina. Si bien ya existía, el desarrollo de políticas sociales focalizadas desarrolladas por el Estado argentino y la emergencia de las organizaciones no gubernamentales como organizaciones legítimas de la ayuda social permitieron a Caritas construirse como una institución legítima y profesionalizada en la gestión de la ayuda social. 
ingleses hacia fines del XIX estuvo durante algunos años restringido a equipos que se conformaban en espacios sociales que reunían a esos grupos nacionales (Archetti 2003). En 1899 se crea la Unión Argentina de Rugby (UAR), la primera unión conformada por jugadores ingleses y no ingleses. Desde entonces se crearán clubes conformados por sectores sociales medios y altos, muchos de los cuales también practicaban fútbol y otros deportes de origen inglés, que, en cuanto europeo, mantenía un halo de prestigio en las elites locales (Losada 2009).

La extensión del deporte moderno que siguió la expansión imperial inglesa produjo nuevas relaciones entre elites y sectores sociales subordinados, tanto en el plano del enfrentamiento deportivo, como en la delimitación de torneos y de deportes. Ese fue el proceso de expansión del rugby inglés y la separación a fines del siglo XIX en dos organizaciones distintas, Rugby Union vinculada a sectores educados más aristocráticos, y Rugby League, vinculada a sectores trabajadores que demandaban pago por su dedicación al deporte (Elias y Dunning 1992). El mismo proceso reaparece para el caso argentino a fines del siglo XX, desde que en 1995 el rugby empieza su conversión profesional a nivel global. El caso de CUBA es paradigmático: cada vez que se profesionalizaba algún deporte de los muchos que se practicaban en el club - como el box o el fútbol -, el club abandonaba las ligas deportivas, y sus socios continuaban practicando el deporte en ligas amateurs.

Sin negar su influencia y valorada efectividad como medio de moralización de las juventudes - y como medio de control social y de producción de la masculinidad (Bourdieu 1988) -, el rugby argentino nunca expandió sus fronteras hacia los sectores populares, donde el fútbol tuvo y tiene relevancia, siendo un deporte tanto popular como transclasista, y un medio de ascenso social. En el campo simbólico de las prácticas deportivas el rugby y el fútbol se construyen mutuamente como alteridades de clase. Aunque jóvenes rugbiers de sectores privilegiados también jueguen al fútbol en sus tiempos libres, o en algún torneo amateur en los clubes, lo inverso no sucede. Los jóvenes de sectores populares juegan al fútbol y con él se identifican, en cuanto práctica cotidiana y oportunidad de movilidad social, sin tiempo, interés ni condiciones económicas para hacer del rugby una práctica propia, aún.

\section{LA PROFESIONALIZACIÓN DEL RUGBY MASCULINO: MORALIZAR EL DINERO}

Agustín tiene 24 años, es rugbier en CUBA y acaba de finalizar su carrera universitaria de administrador de empresas. Como muchos de sus amigos es un apasionado del rugby: lo juega desde que tiene seis años. Empezó junto a otros niños de su edad que eran amigos y vecinos del barrio cerrado que CUBA posee en el Gran Buenos Aires. Entre sus inquietudes, Agustín experimenta 
las tensiones del proceso de profesionalización. Ha realizado un gran esfuerzo por mejorar su performance como jugador de la primera división del rugby, y llevar "sus estudios al día", todo ello sostenido por su familia, con quienes aún vive. Aunque el rugby que él practicaba en ese momento era amateur - en la Argentina no existía ningún equipo profesional sino hasta 2016 -, ya experimentaba nuevas condiciones que los mismos rugbiers se imponían a sí mismos para mejorar su nivel de juego.

Con frecuencia observaba que, antes de sus entrenamientos, los jugadores consumían suplementos - complementación proteica por ejemplo - y, al conversar con ellos, se evidenciaba cómo aun siendo amateurs, sistematizaban su entrenamiento y su alimentación como si fueran jugadores profesionales. El rugby se profesionalizaba en la producción corporal del deporte amateur, por el deseo de los jugadores de mejorar, proceso posibilitado, además, por las mismas familias que sostenían económicamente y afectivamente a sus futuros herederos. El capital económico que circula al interior de las familias, para sostener la sociabilidad e incluso la intensificación cuasi profesional de los entrenamientos deportivos de sus hijos, es legítimo porque forma parte de las estrategias familiares de reproducción social. Sus hijos no necesitan una contraprestación a un "externo" para recibir ese dinero - como un contrato profesional -, siempre y cuando sostengan su responsabilidad con el estudio, la familia, las amistades y el mismo rugby. El capital económico circula al interior de la familia y allí su flujo es legítimo.

La crisis socioeconómica que eclosiona en 200 l encontró a jóvenes de familias de sectores medios-altos buscando una carrera profesional deportiva en el exterior, proceso que implicó la migración de muchos jugadores argentinos en los primeros años de los 2000, hacia las naciones del norte global (Irlanda, Francia, Inglaterra, Italia, etc.). Se instaló un sistema de circulación de jugadores que los actores locales si bien apoyaron - se trata de sus hijos o sobrinos, en muchos casos - no dejaron de mirar con recelo, ya que así se alteraba el modo normalizado de construir la trayectoria juvenil en relación constante con la familia, el club y la universidad (Fuentes y Guinness 2018). Años después, la profesionalización del rugby ya era un hecho: en 2010, por ejemplo, destacados jugadores elegidos por la misma UAR para integrar el seleccionado nacional jugaban profesionalmente en equipos de rugby inglés, francés, irlandés, etc. Este fenómeno de migración y profesionalización global les permite a los actores locales considerar al capital económico de la industria deportiva como ilegítimo, porque además de alterar el modo en que se reproduce la elite local, el encuentro entre lo global y lo local es visto como la intrusión de una fuerza extranjera.

Otras condiciones hicieron posible la profesionalización: el crecimiento del público del rugby, concomitante con la expansión de la industria televisiva. En la década del 90 se privatizan en Argentina los canales de televisión, se 
expande la televisión por cable, y se consagra el fútbol como industria televisiva, que luego es acompañada por la espectacularización de otros deportes como el rugby. Los partidos de "Los Pumas" - nombre del equipo nacional adquieren desde entonces cada vez mayor audiencia, indicando los flujos de recursos económicos reales y potenciales, frente a los cuales algunos actores del mundo del rugby reaccionan construyendo una distancia moral. En 2013, por ejemplo, las autoridades de CUBA se resistían a que las transmisiones que efectuaba la cadena global de deportes ESPN -que tiene los derechos para la transmisión del rugby local - les impusiera cartelería publicitaria en la cancha o en sus alrededores. Según me explicaba un socio del club, renunciaban de modo explícito a la ganancia económica, frente a la "industria televisiva" y al resto de los clubes de rugby, dando un ejemplo moral en momentos donde el rugby llegaba a nuevos públicos.

En ese campo donde se conjugan desigualdades locales y procesos globales, la posición de las uniones de rugby y de los clubes fue modificándose, ganando legitimidad gradualmente la que está a favor de una mayor profesionalización del rugby argentino. La International Rugby Board (IRB) - hoy World Rugby -, organismo que nuclea a las uniones de rugby del norte y sur global, comprometió desde 2011 el envío de recursos económicos para la implementación de centros intensivos de entrenamientos, que implicaban la dedicación diaria de los jugadores al rugby, con el pago de una beca. Al mismo tiempo, aumenta la audiencia del rugby ante nuevos públicos, en el que las elites se exponen a otros sectores sociales interesados en practicarlo, en un proceso que los defensores del amateurismo no terminan de manejar, sino que es liderado por el movimiento de capitales económicos.

Otros referentes del rugby con los que conversé en distintos momentos señalaban que en la profesionalización los jugadores ya no van a pelear por la camiseta, sino "por la guita que les pagan como en el fútbol", y ello atraería a nuevos sectores sociales percibidos como externos, "de afuera", que buscan hacer del rugby una fuente de ingresos. La relación de los actores con el dinero es significada como impropia moralmente en un flujo que se sale del control del espacio familiar. Allí es cuando se construye una alteridad de clase en términos morales: el propio valor del rugby frente al fútbol y al dinero. Ser un deportista profesional los igualaría al fútbol, donde lo que importa - según la perspectiva amateur - no es la finalidad amistosa, lúdica y reglada del juego, "el respeto al referí y a las reglas, así lo quieras matar", sino dejar todo por la "guita, un mejor contrato, el éxito" [Enrique, rugbier de CUBA].

Como hemos documentado (Fuentes 2012, 2015a), las estrategias de diferenciación social en este sector implican la consideración negativa de aquellos que, según la perspectiva de los establecidos, han hecho demasiado rápidamente su fortuna económica y, además, no tienen el mismo ethos en cuanto a 
la ostentación de su riqueza. Aunque los "nuevos ricos", como los llaman, sean clasificados como tales, muchos de ellos ya se hallan al interior del sector social de las familias tradicionales del rugby y el catolicismo de Buenos Aires, porque ingresaron al circuito socioeducativo, heterogeneizando las elites.

Mientras realizaba el trabajo de campo, varios referentes me relataron una antigua frase que organiza la distinción del rugby en relación al deporte profesional por excelencia: "el fútbol es un juego de caballeros jugado por animales y el rugby es un juego de animales jugado por caballeros". De este modo reafirman el origen honorable de quienes juegan al rugby, por más que durante el juego la fiereza y la agresividad parezcan organizar la práctica. La visibilidad pública, la expansión y profesionalización hacen que el valor social construido de modos morales y por medio de la educación formal introduzca otra escala y criterios para organizar la posición social y moral de los sucesores en este grupo social. Pero no se trata solamente de una disputa moral, en el sentido de marcos valorativos que solo se oponen en su caracterización sobre lo correcto o adecuado.

La batalla moral señala el contacto simbólico y material entre jóvenes y actores de distintos sectores y clases. La reivindicación del caballero se entiende en la Argentina como una distinción que apela al autocontrol y a una masculinidad antiplebeya (Alabarces 2013), opuesta a una masiva y popular en el fútbol.

"Mientras observo desde un lateral el entrenamiento de rugby converso con parte del equipo de entrenadores. Justo llega un jugador que llama mucho la atención, parece más grande en edad. Me dicen que tiene como 30 años. Me cuentan que acaba de volver de Francia, se le terminó el contrato con un club de ese país y mientras ve qué hacer de su vida, está entrenando y jugando acá (es socio del club). Es abogado pero nunca ejerció, siempre jugó al rugby y ahora se le hace difícil, compite con pibes más chicos que él, incluso que ya tienen experiencia" [diario de campo, julio de 2014].

Lo que altera la profesionalización, con la introducción formal del dinero como retribución, es la hegemonía del modelo de construcción de la trayectoria juvenil de los jóvenes de estos sectores: la educación universitaria que desemboca en el ejercicio profesional.

Por medio del profesionalismo, los jóvenes sucesores perderían la distinción moral que subordina al capital económico. Se ponen en juego las fronteras sociales y morales en relación con otros sectores sociales y el deporte es un espacio privilegiado para comprenderlo. El rugbier emigrado a Francia simboliza la pérdida de la distinción en relación al fútbol, quedar atrapado entre "contratos" pasados y futuros, sin los capitales educativos y sociales que funcionen como soporte. El actual momento de cambio del rugby muestra un 
rostro de la configuración y pertenencia de clase en la Argentina, donde los sectores de elites ya establecidos se construyen a sí mismos como una clase moral, frente a una alteridad donde están ubicados el capital económico, los recién llegados ("nuevos ricos") y el fútbol.

La emergencia del contrato profesional se instaló de modo explícito con la creación de la primera franquicia profesional de la UAR en 2016, los Jaguares. El contrato instala una relación directa con el capital económico como valorizador de la trayectoria social, que pone en escena una moralidad que las elites atribuyen a otra clase social. Como han mostrado otras investigaciones, las elites argentinas nunca hicieron gala de una diferencia en su volumen de capital económico, tal vez por la inestabilidad del mismo y de la sociedad, sino que construyen sus distinciones en función de capitales o recursos educativos, mediante asociaciones con la historia de la nación (Gessaghi 2016), o el logro del éxito individual (Chaves, Fuentes y Vecino 2016).

El dinero es puesto como un intruso porque simbólicamente altera la pureza moral de una clase que se siente amenazada. Por un lado, por fuerzas extranjeras, lo cual quiere decir por una clase o un poder superior a ellos. Por otro lado, el dinero como posible igualador (Simmel 1986 [1903]) es temido. El rugby es un campo donde se pone en juego intentos de diferenciación en tiempos de masificación, denuncia moral en tiempos de globalización y espectacularización de los deportes y valores morales justo cuando el dinero instala nuevos modos de jerarquización: se construye la desigualdad social de distintos modos a los que reinaron hasta entonces.

"GENTE IMPORTANTE" Y "HUMANA":

PRÁCTICAS Y SENTIDOS DE LA EDUCACIÓN SOLIDARIA

A lo largo del trabajo de campo me encontré con un conjunto heterogéneo de acciones denominadas solidarias realizadas por jóvenes católicos de elite, como campañas y colectas de recursos para familias en situación de pobreza, realizadas en el marco de fundaciones vinculadas al mundo del rugby, actividades donde se enseñan "valores" por medio del rugby, y acciones realizadas por instituciones católicas, tanto de evangelización como de promoción social. Muchas de estas actividades son organizadas en el ámbito de la educación formal en escuelas secundarias y universidades.

Si los jóvenes asistieron a una escuela con bachillerato internacional, participaron del "community service", un espacio destinado al desarrollo de actividades comunitarias; en otras escuelas desarrollaron proyectos de aprendizaje-servicio, además de actividades pastorales católicas. Santa Julia, una de las escuelas a donde concurren los socios de dos importantes clubes de rugby de la zona norte de Buenos Aires, es caracterizada como "solidaria", con valores, donde se enseña "otra cosa" que el éxito, la búsqueda de la plata, una 
educación "más humana", según refieren madres entrevistadas y se enfatiza en los actores escolares. Docentes del colegio ponderan que sus estudiantes tengan esa visión "sobre el otro", la pobreza, puesto que "el día de mañana van a ocupar lugares importantes en la sociedad". Me encontré con las mismas intenciones, de formar gente "importante" con una visión solidaria de la vida en otros espacios institucionales de los que participan jóvenes de sectores medios-altos y altos.

En una universidad católica participé de algunas de las actividades de "compromiso social”, prácticas pre-profesionales y/o de voluntariados en las villas de emergencia de la Ciudad de Buenos Aires, en hospitales públicos, etc. Cuando conversaba con estudiantes o profesores aparecía el interés por formar o ser un profesional "más humano", ubicando a la universidad católica como una institución cuyos miembros sean "interpelados por esa realidad más sufriente". Me interesa remarcar el énfasis en la construcción de un joven "más humano". No se trata tanto de uno más religioso o católico. Se enfatiza el ideal de estar más comprometido con la realidad, proyectando un futuro profesional adulto sensible en su vida cotidiana para con los pobres. En un contexto donde crece el pluralismo y el cuentapropismo religioso (Mallimaci 2015), las instituciones católicas buscan resignificar la tradicional caridad que practicaban los padres o abuelos de estos jóvenes, construyendo posiciones y relaciones de clase que no necesariamente están vinculadas al origen o a la apelación a la nación, ni tampoco a causas de transformación social y política.

Se trata más bien de construir una práctica de la cercanía y de ayuda puntual, establecer relaciones concretas cara a cara con los pobres, y extender esos modos que se pretenden profesionales, en un doble sentido. Por un lado, porque si bien algunos se denominan "voluntariados" están coordinados por personal especializado (profesores, psicólogas, trabajadoras sociales, etc.), en lo que algunos consultados plantean como un rostro más neutral - en términos políticos e ideológicos - y al mismo tiempo más "serio" que la actividad que entre los pobres realizan otros actores en competencia con las instituciones católicas: partidos políticos e iglesias evangélicas. Por otro lado, porque apuestan a la formación de profesionales con un sentido solidario de su práctica. La formación que brindan las escuelas y universidades católicas se posiciona entonces como una educación de personas educadas y "de bien", sensibles. Aunque en algunos espacios de talleres y seminarios se aborde el problema de la "desigualdad" en el acceso a la vivienda, por ejemplo, las prácticas realizadas apuntan a actuar en la desigualdad para "hacer algo, un granito de arena", como nos relataba un joven estudiante universitario durante un taller de apoyo escolar en la villa miseria.

Sin embargo, el número de estudiantes de la universidad privada que participan de las actividades solidarias constituyen una minoría. Hacia dentro de la universidad, los actores más "comprometidos" con los pobres encontrarían 
cierta resistencia para que estas prácticas solidarias se extiendan: se trata de jóvenes de sectores medios-altos y "de clase alta" - relataba un entrevistado -, que "seguramente dirían iir a la villa?" y no se le ocurriría participar de una práctica profesional en ese contexto. La misión de "humanizar" es una misión ad intra de la institución, y de los sujetos de clases con capitales económicos considerables que pasan por ella. Se trata de hacer más sensibles a jóvenes que se supone no lo son por la abundancia de recursos económicos, que a veces se concentra en la imagen del "nuevo rico". El proceso de fragmentación social y posterior recomposición de los ingresos de los sectores postergados (Kessler 2014) implicó también una recomposición de la posición de los sectores privilegiados, que apuestan a un contacto cara a cara con la pobreza, no solo porque ello los ubica en una posición de distinción moral en cuanto dadores de ayuda. También les permite construir redes donde a futuro pueden movilizar recursos, en función de una apuesta por posicionarse como sector que lidere una sociedad desigual. Conocer de cerca la pobreza es un activo para el futuro de estos jóvenes "importantes". Aunque la pobreza haya disminuido, su presencia estructural no se ha eliminado, como tampoco la riqueza.

El crecimiento de las desigualdades condiciona a los actores a mirar la concentración de recursos en manos propias o ajenas de nuevos modos. Mientras participaba de una "misión católica" de estudiantes universitarios en una villa miseria, la inquietud por la riqueza se hacía onmipresente. Los jóvenes pobres de la villa se sorprendían de la calidez y amistad de los jóvenes de la universidad privada, mientras estos encontraban a los primeros faltos de todo peligro, cercanos y "buenos", problematizando ambos sus prejuicios acerca de la riqueza y la pobreza. Pero en los momentos de oración que compartían solamente los jóvenes de elite, la problematización constante era la posesión de la riqueza y la culpa de "haber nacido sin necesidades", en un lugar "privilegiado".

En las relaciones que establecen estos jóvenes de elite con los jóvenes pobres se legitima una posición social en cuanto posición moral, que diferencia (o convierte) a los jóvenes con compromiso de aquellos que sólo buscan o "tienen mucha guita" (conversación con Juana, estudiante universitaria). Las prácticas solidarias no solo se explican por un nuevo rostro y configuración de las desigualdades sociales en la relación riqueza-pobreza; sino también porque los "nuevos ricos" aparecieron en los espacios de sociabilidad que antes solo detentaban sectores con mayor antigüedad en las posiciones altas. En este campo de prácticas solidarias el dinero y su acumulación son construidos como el otro moral.

La educación no es solo el contexto en el que se producen los jóvenes solidarios. Es también el contenido de su posición y discursos morales. A lo largo del trabajo de campo, pude ver que los jóvenes que realizan estas actividades solidarias no hablan mucho de "dios": hablan todo el tiempo de la "educación", 
de la necesidad de educarse... Lo que "salva es la educación”, dice Marina, siguiendo al juez. La clase social es una experiencia que se construye significando y distribuyendo una idea de progreso, la fe en la educación, al mismo tiempo que se emprenden estas actividades de edificación moral de los subordinados: el progreso de los pobres supone una ganancia para todos, sobre todo para quien da la ayuda.

Los procesos de transformación social han condicionado a que estos sectores altos, por medio de las prácticas educativas solidarias, desplacen parcialmente el núcleo de su acción centrado en la divulgación del catecismo católico, poniendo nuevamente en el centro la promoción o intervención social, como había sucedido en la década del 60 y 70 . Solo que ya no se realiza con el propósito de cambio o revolución social y política, sino como parte de una responsabilidad más individual asumida en relación a los privilegios que comporta el dinero y la educación universitaria hecha tradición en sus familias. La educación puede darse y extenderse, pero no el capital económico, que es significado y puesto como un valor que debe subordinarse: si hay desigualdades, las mismas son explicadas como desigualdades de oportunidades, méritos o esfuerzos individuales, no como condición estructural.

\section{CIERRE: EL DINERO Y UNA CLASE MORAL}

La manera de construir una juventud distinguida está posibilitada por la posesión de un determinado capital económico y un capital escolar acumulado en las familias. El rugby como deporte emblema y la educación solidaria funcionan como prácticas que distinguen a estos jóvenes en relación a los jóvenes de sectores populares, por la posesión de esos recursos y por los valores morales asociados a ellos, ya que juegan un rol crucial en la pertenencia a la clase y la construcción de sus alteridades.

Los sectores de elite necesitan de otros en posiciones económicas subordinadas para significar y dotar de legitimidad lo que da sentido a la desigualdad que los distancia: la posesión del capital económico, la acumulación del capital escolar. En ambas prácticas, aún en un momento de transformación profunda como el que atraviesa el rugby argentino, la insistencia sobre el amateurismo muestra el trabajo que estos actores realizan para imponer una determinada visión sobre su posición social, que se pretende legítima. ${ }^{11}$ Las prácticas deportivas muestran cómo una clase ve limitada su fortaleza para legitimarse en cuanto elite y mantener sus rasgos de distinción. Frente a la profesionalización que no manejan, movilizan una pertenencia a una clase a la que no se llega

11 En lo que Bourdieu (2013) caracterizaría como las luchas por la imposición del principio de dominación dominante, es decir, el modo en que los actores disputan en el campo del poder los principios, valores, discursos, saberes con los cuales legitiman su visión de la sociedad y el lugar que ocupan en ella. 
fácilmente, ya que el capital económico no bastaría, es necesaria una probidad moral que es necesario adquirir. Rechazar la necesidad o el deseo de mayor ganancia económica es un modo de reposicionar una distinción moral. Aunque estos sectores ya no gobiernen los criterios de pertenencia social a unas elites que se han heterogeneizado, poseen un peso importante en cómo se delimitan aún las fronteras sociales y morales de pertenencia.

La construcción del valor de una juventud distinguida se arma en función de que el dinero no ingrese como impureza a reglar las trayectorias que construyen estos jóvenes, ya que la circulación legítima del dinero está en el espacio familiar, de padres a hijos. Los actores pueden transformar sus capitales económicos en un valor trascendente que no es tocado o reglado por el dinero, y que se estiliza en la pertenencia a una clase moral, donde la posesión del capital económico es subordinada a una distinción simbólica, como ser "humano", "solidario", "buen compañero" o "leal". La construcción de una trascendencia valorativa no sólo crearía una comunidad imaginada, un grupo social con cierta mística particular y distintiva - que es lo que se proponen la educación solidaria y el rugby masculino. En ambas prácticas el dinero funciona como un organizador valorativo (Zelizer 2011) y por medio del mismo se construyen explícita o implícitamente las alteridades de clase en clave moral. Las transformaciones del deporte, como hemos visto, constituyen un espacio privilegiado para entender un proceso social más amplio: los cambios en las relaciones entre clases.

La extensión de la educación solidaria indica el intento de las instituciones que conforman circuitos de sociabilidad y educativos prestigiosos de sostener una mayor demanda de contacto interclases. La pobreza puede cambiar en su tamaño o en sus necesidades, pero siempre está, y ese es el aprendizaje que desarrollaron las elites en Buenos Aires y que expanden por medio de las instituciones educativas: educarse y prepararse para actuar en la pobreza de una sociedad desigual es una apuesta por erigirse como personas importantes en una sociedad cambiante, pero cuya pobreza permanece.

El proceso que mueve a la construcción de un prestigio está dado por una condición de posibilidad estructural: la posesión de capital económico, junto a la capacidad de invocar antigüedad (Lima 2003), aún cuando se trate de una institución que supuestamente refuerza la lógica del mérito, como son las universidades modernas. Ahora los méritos se predican como un logro individual: salvarse por medio de la educación, un proyecto que igualaría a pobres y a ricos, solo que neutraliza la desigualdad económica. La desigualdad se sostiene en una relación moral donde quien "ayuda" se ubica como modelo de logro meritocrático e individual. Los sujetos son hechos clase social - clases de personas - en operaciones de clasificación donde se pone en juego "valores" que se definen relacionalmente, tanto en el contacto con los sectores empobrecidos como en el vínculo y el sentido que se le da al capital económico. 
Si bien las elites siempre construyeron imágenes de los otros a los que subordinan, la particularidad aquí analizada reside en la articulación entre clase y moral. Si antes se podía invocar amateurismo deportivo y caridad católica como marcadores de clase, los mismos parecen hoy no ser suficientes para sostener las fronteras sociales y morales (Lamont 1992) con otros actores: los que se enriquecieron recientemente, los judíos o los pobres de siempre. De esta manera, los sectores privilegiados que se reconocen como católicos se reposicionan en una sociedad que impugna las desigualdades, pero que el deporte y las prácticas solidarias permiten salvar, como si no existieran esas jerarquías. En este sentido la solidaridad presenta una gran ironía: es imposible entenderla sin la desigualdad que organiza la relación entre ricos y pobres.

\section{BIBLIOGRAFÍA}

ALABARCES, Pablo, 2006, "Esporte”, en Emir Sader et al. (coords.), Enciclopédia Contemporânea da América Latina e do Caribe. Rio de Janeiro, Boitempo/Clacso, 493-501.

ALABARCES, Pablo, 2013, "Fútbol, leonas, rugbiers y patria: el nacionalismo deportivo y las mercancías", Nueva Sociedad, 248: 28-42, disponible en < http://nuso.org/articulo/fut bol-leonas-rugbiers-y-patria-el-nacionalismo-deportivo-y-las-mercancias/ > (última consulta en febrero 2018).

ARCHETTI, Eduardo, 2003, Masculinidades: Fútbol, Tango y Polo en la Argentina. Buenos Aires, Antropofagia.

BADARÓ, Máximo, 2009, Militares o Ciudadanos: La Formación de los Oficiales del Ejército Argentino. Buenos Aires, Prometeo.

BESNIER, Niko, 2012, “The athlete's body and the global condition: Tongan rugby players in Japan”, American Ethnologist, 39: 491-510, disponible en < https://doi.org/10.1 1 1 1/j.154 8-1425.2012.01377.x > (última consulta en febrero 2018).

BESNIER, Niko, y Susan BROWNELL, 2012, "Sport, modernity, and the body", Annual Review of Anthropology, 41: 443-459.

BOURDieU, Pierre, 1988, La Distinción: Criterios y Bases Sociales del Gusto. Madrid, Taurus.

BOURDIEU, Pierre, 2013, La Nobleza de Estado: Educación de Elite y Espíritu de Cuerpo. Buenos Aires, Siglo XXI.

CHAVES, Mariana, Sebastián FUENTES, y Luisa VECINO, 2016, Experiencias Juveniles de Desigualdad: Fronteras y Merecimientos en Sectores Populares, Medios Altos y Altos. Buenos Aires, Grupo Editor Universitario, disponible en < http://biblioteca.clacso.edu.ar/clacso/gt/20 171218041618/Experiencias_juveniles_de_la_desigualdad.pdf > (última consulta en febrero 2018).

ELIAS, Norbert, y Eric DUNNING, 1992, Deporte y Ocio en el Proceso de la Civilización. México, DF, Fondo de Cultura Económica. 
FONSECA, Claudia, 2005, "La clase social y su recusación etnográfica”, Etnografías Contemporáneas, 1 (1): 117-138.

FUENTES, Sebastián, 2012, “Los jóvenes y la 'guita': tensiones en torno a la profesionalización del rugby masculino en Buenos Aires", Revista Esporte e Sociedade, 20 (7): 23-49, disponible en < http://www.uff.br/esportesociedade/index.html?ed=20,autor $=2>$ (última consulta en febrero 2018).

FUENTES, Sebastián, 2015a, Educación y Sociabilidad en las Elites de Buenos Aires. Buenos Aires, Universidad Nacional de San Martín, tesis doctoral.

FUENTES, Sebastián, 2015b, "La formación de los cuerpos jóvenes y su diversidad: un estudio sobre la producción social de los cuerpos masculinos y distinguidos en el rugby de Buenos Aires", Revista Latinoamericana de Cuerpos, Emociones y Sociedad, 7 (18): 66-82, disponible en < http://www.relaces.com.ar/index.php/relaces/article/view/306/262 > (última consulta en febrero 2018).

FUENTES, Sebastián, 2016, “La extensión universitaria en Buenos Aires: legitimidades y transformaciones recientes”, Ciencia, Docencia y Tecnología, 53: 234-267, disponible en $<$ http://ref.scielo.org/k7b5h9> (última consulta en febrero 2018).

FUENTES, Sebastián, y Daniel GUINNESS, 2018, “Nacionalismos deportivos con 'clase': el rugby argentino en la era profesional/global", Antipoda: Revista de Antropología y Arqueología, 30: 85-105, disponible en < https://dx.doi.org/10.7440/antipoda30.2018.05> (última consulta en febrero 2018).

GESSAGHI, Victoria, 2016, La Educación de la Clase Alta Argentina: Entre la Herencia y el Mérito. Buenos Aires, Siglo XXI.

GUSMÃO, Neusa Maria Mendes de, 2009, "Entrelugares: antropologia e educação no Brasil”, Educação, 34 (1): 29-46.

HEREDIA, Mariana, 2005, "La sociología en las alturas: aproximaciones al estudio de las clases/elites dominantes en la Argentina”, Revista Apuntes de Investigación del CECYP, IX (10): 103-126.

KESSLER, Gabriel, 2014, Controversias sobre la Desigualdad: Argentina, 2003-2013. Buenos Aires, Fondo de Cultura Económica.

KHAN, Shamus, 201 1, Privilege: The Making of an Adolescent Elite at St. Paul's School. Princeton, Princeton University Press.

LAMONT, Michèle, 1992, Money, Moral and Manners: The Culture of the French and the American Upper-Middle Classes. Chicago, The University of Chicago Press.

LIMA, Antónia Pedroso de, 2000, “'How did I become a leader in my family firm?': assets for succession in contemporary Lisbon financial elites”, en João de Pina-Cabral y Antónia Pedroso de Lima (coords.), Elites: Choice, Leadership, and Succession. Oxford, Berg, 31-52.

LIMA, Antónia Pedroso de, 2003, Grandes Famílias, Grandes Empresas: Ensaio Antropológico sobre Uma Elite de Lisboa. Lisboa, Publicações Dom Quixote.

LOMNITZ, Larissa Adler, 1982, "Horizontal and vertical relations and the social structure or urban Mexico", Latin American Research Review, 17 (2): 51-74.

LOSADA, Leandro, 2009, Historia de las Elites en la Argentina: Desde la Conquista hasta el Surgimiento del Peronismo. Buenos Aires, Sudamericana.

MAllimaCI, Fortunato, 2015, El Mito de la Argentina Laica: Catolicismo, Política y Estado. Buenos Aires, Capital Intelectual.

MANZANO, Valeria, 2010, "Cultura, política y movimiento estudiantil secundario en la Argentina de la segunda mitad del siglo XX", Propuesta Educativa, 35: 41-52, disponible 
en < http://propuestaeducativa.flacso.org.ar/archivos/dossier_articulos/50.pdf > (última consulta en febrero 2018).

MARCUS, George, 2000, “The deep legacies of dynastic subjectivity: the resonances of a famous familiy identity in private and public spheres", en Antónia Pedroso de Lima e João de Pina-Cabral (coords.), Elites: Choice, Leadership, and Succession. Oxford, Berg, 9-29.

MÉNDEZ, Alicia, 2013, El Colegio: La Formación de Una Elite Meritocrática en el Nacional Buenos Aires. Buenos Aires, Sudamericana.

NADER, Laura, 1969, “Up the anthropologist: perspectives gained from 'studying up', en Dell Hymes (coord.), Reinventing Anthropology. Nueva York, Pantheon Books, 284-311.

NEUFELD, María R., 2000, "Familias y escuelas: la perspectiva de la antropología social", Revista Ensayos y Experiencias, 36: 3-13.

PALERMO, Elisa, 2010, "Procesos de identificación étnica y clasista entre un grupo de argentino-irlandeses de Buenos Aires”, Cuadernos del IDES, 18: 1-32.

PERISTIANY, J., 1968, “Introducción”, en J. Peristiany, El Concepto del Honor en la Sociedad Mediterránea. Barcelona, Labor, 11-20.

PEROSA, Graziela, 2009, Escola e Destinos Femininos: São Paulo (1950/1960). Belo Horizonte, Argvmentvm Editora.

PISCITElli, Adriana, 2006, Jóias de Família: Gênero e Parentesco em Histórias sobre Grupos Empresariais Brasileiros. Rio de Janeiro, Editora da UFRJ.

PITT-RIVERS, Julian, 1968, "Honor y categoría social”, en J. Peristiany, El Concepto del Honor en la Sociedad Mediterránea. Barcelona, Labor, 21-76.

ROCKWELL, Elsie, 2009, La Experiencia Etnográfica: Historia y Cultura en los Procesos Educativos. Buenos Aires, Paidós.

SIMMEL, Georg, 1986 [1903], "Las grandes ciudades y la vida del espíritu", Cuadernos Políticos, 45: 5-10.

SVAMPA, Maristella, 2001, Los que Ganaron: La Vida en los Countries y Barrios Privados. Buenos Aires, Biblos.

SVAMPA, Maristella, 2004, "Fragmentación espacial y procesos de integración social hacia arriba: socialización, sociabilidad y ciudadanía”, Espiral, XI (31): 55-84, disponible en < http://www.redalyc.org/articulo.oa?id=13803103 > (última consulta en febrero 2018).

TIRAMONTI, Guillermina, y Sandra ZIEGLER, 2008, La Educación de las Elites: Aspiraciones, Estrategias y Oportunidades. Buenos Aires, Paidós.

ZELIZER, Viviana, 2011, El Significado Social del Dinero. Buenos Aires, Fondo de Cultura Económica.

ZIEGLER, Sandra, y Victoria GESSAGHI, 2012, La Formación de las Elites: Investigaciones y Debates en Argentina, Brasil y Francia. Buenos Aires, Manantial. 